\title{
THE LIFE QUALITY OF A CHILD FROM A FOSTER FAMILY IN ROMANIA
}

\author{
Ana Maria Dumitrescu ${ }^{1}$ \\ ${ }^{1}$ Asst. Prof. Dr., Pitesti State University, Romania, amdumitrescu81@yahoo.com
}

\begin{abstract}
As an alternative form of childcare, in Romania foster care is a welfare system that comes to meet the needs of the children who are medically fragile, who have been mistreated or who need specialized services. Most children who benefit from this protection have been traumatized and need medical, psychiatric, educational and special social care, and others come here because their biological families are unable or unequipped to manage care for a child with serious emotional issues or behavioral problems. The placement treatment is based on the premise that foster parents can serve as an important provider of therapy in the daily interactions with the child, that therapy should not be practiced only by a clinician and that the psychological needs of children can be best achieved in a family environment. Therefore, success of the placement to a specialist carer depends on the attachment that is created between the family of the carer and the child taken into care but also on the support received by the family from the community.

The aim of this study is to find out the quality of life of children placed in a foster family. The standard of living is further understood as satisfaction of the basic needs (both spiritual and existential) of a child.The analysis of the problem was based on a qualitative research firstly using observation as a method precursory of all the other tools and direct investigation of the face-to-face type. The sample consisted of two groups of respondents - children and foster parents. It should be stressed that the investigation into family life is very difficult because it may interfere with intimacy. In the case of the questionnaire prepared for children, it was necessary for it to be made as simple as possible without going too deep into their privacy. The relatively simple and comprehensive questionnaire makes it easy to assess the quality of life of children placed in foster families and the fact that the issue is studied from two perspectives, using two different questionnaires provides the possibility to collect more varied information, at least some of which can be compared. The results of this study demonstrate that the placement of children in professional foster care increases their quality of life, bringing major contributions to their recovery and social integration.
\end{abstract}

Keywords: social protection, foster family, quality of life, research method

\section{INTRODUCTION}

In Romania, the communist period has seriously affected the image of the child in society, in particular of the child in a protection system, which generated many social problems. Later on, the transition from socialism to capitalism was very difficult in this area, since the system of child protection was forced to face a reality 
that was very difficult to manage, a reality that was inherited from the old regime, namely a high number of institutionalized children, the lack of intervention programs, the lack of consistency in income distribution, lack of coherent, prospective policies for the cultural sector. However, huge progress was made in legislation, concerning the decentralization of services, the closure of large residential institutions and the provision of alternatives for the placement of children.

One of these solutions is the placement in foster care to a professional maternal assistant (foster parent) which, in Romania, is the latest profession in the field of child protection, but which in recent years has managed to enjoy success. According to Petre (2002), in Romania the foster family is represented by the placement family, namely "family attested by the competent authorities and ready to provide protection to children in difficulty placed under care or committed for a determined period of time" (p.332).

Children enter foster care for several reasons. For some children the journey begins from birth, when it is clear that the mother cannot take care of the new-born child. Other children come to the attention of child protection when a teacher, a social worker, a police officer, or a neighbour reported the child's involvement in a case of abuse, neglect, maltreatment or abandonment of their families, so they require special medical, psychiatric, social and education care. Others come here because their biological families are unable or are not equipped to manage care for a child with serious or very serious emotional, physical or behavioural problems. These fragile families are very poor, living in high-risk environments, and often face intractable problems as substance abuse, mental illness, physical illness, domestic violence, and inadequate housing.

Foster care treatment is based on the principle that these parents can be the main suppliers of therapy through daily interaction with these children and that therapy should not be practised only by the clinician (Gabor \& Kammerer, 1983). The family environment can provide children, in addition to their basic needs, with the psychological needs that are so essential in their development. But the success of the placement depends on the one hand on the links between the placement family and the child, as well as on the community involvement in supporting the family. Families who take in foster children with disabilities may face special problems requiring specific additional resources in order to operate in the same way as a family that takes care of children without disabilities (Buboltz \& Whiren, 1984). It is therefore important to identify these families' needs in order to support them.

Moreover, the foster family is considered a more advantageous form of child care because the maternal assistant is required under the provisions in force to attend training courses organized by the employer as a condition not only to obtain the certificate, but also to maintain the activity. The issue of participation in continuous training and informing activities is also one of the elements that are taken into account when reassessing the professional maternal assistant. The Framework Programme Developed by the National Authority for Child Protection has been designed so as the training of foster parents should include themes from several areas: legal framework of child protection rights and child development, care of a healthy and sick child, childcare, pedagogy, rights and obligations of the maternal and professional foster parent, child's self-identity formation, theory of attachment and consequences of attachment disorders, as well as the prevention of child abuse and neglect (D. Buzducea, 2010).

So there are specialist centres dealing with social support supervising the implementation of the methods of parenting appropriate to the children placed in these families. But these centres should provide psychological and pedagogical aid and collect essential information about children placed in foster families. The question is, though, if, in spite of all operating mechanisms, we still have enough information about children in foster families or if we are able to appreciate the quality of their lives and understand their feelings.

In the study conducted in 2000 in Romania, Bucharest Early Intervention Project (BEIP) a program was implemented designed to assess whether the placement of a child in foster care can enhance the development of a child who has been deprived of his/her family environment and institutionalised. The results of this study demonstrate that family foster care for young children is superior to institutional care. As compared to children who remained in institutional care, children in the intervention group demonstrated better attention levels at 42 months of age, more positive affect at both 30 and 42 months, and were less likely to experience internalizing disorders, including anxiety disorders, at 54 months (Ghera et al. 2009; Zeanah et al. 2009 ). Another study with this population found more positive change in attachment status at 42 months among children in the intervention group (Smyke et al. 2010). The intervention group showed improved cognitive development as measured both by standardized cognitive assessments at 42 and 54 months (Nelson et al. 2007 ) and improved EEG power and coherence at 42 months (Marshallet al. 2012). The BEIP thus provides critical, potentially policy-altering evidence for countries in which institutional care is a placement option.

This paper aims to complement this picture by investigating the quality of life of children placed with foster 
parents. The study was conducted in a region in southern Romania, namely the Arges County, with the objective of investigating the living standard conceived as satisfying the basic needs (both spiritual and existential) of a child under this form of protection. The research methodology includes qualitative and quantitative methods that will explore perspectives of both the child and the foster parent. The use of mixed methods permitted to increase the validity and reliability of data. As a result, research has revealed that placing children in professional foster care increases their quality of life, bringing major contributions to their physical and psychological recovery, to their reintegration in the biological or foster family and to their social integration.

\section{MATERIALS AND METHODS}

The analysis of the topic was based on a qualitative and quantitative research using primarily observation as a method precursory of other tools and the method of direct investigation of the face-to-face type. A method of the intensive type was mainly used: the interview and questionnaire composed of questions that focused on the following indicators: home comfort and standard of living, family health, methods of raising children, the schooling of children, ways of spending leisure time, the emotional state of the child, the foster family's individual resources, goods and services which children have access to, satisfaction or dissatisfaction of children (happiness, frustration). The methodology for these interviews and questionnaires was based on a theoretical approach allowing the identification of relevant elements of quality of these children's life.

There were chosen two groups of respondents, namely children and foster parents. Initially, the first problem that emerged was related to the fact that the pre-schoolers were unable to complete the questionnaire themselves. It was decided that pre-schoolers be interviewed on the same questions as pupils except for the questions closely linked to school. So two versions of the questionnaire were prepared, one designed for children and one for foster parents.

It must be emphasized that family life investigation is very difficult because it can interfere with intimacy (Mariusz J. Ligarski, 2010). In the case of the questionnaire prepared for children, the issue has been addressed as simply as possible without going too far into their private lives.

The first part of the questionnaire focused on gathering information on housing, individual and community resources (number of rooms, types of facilities available, if the child has its own place to study and relax, security, financial resources, how the community supports the family). Part two of the questionnaire concerned the child, focusing mainly on his/her health (degree of disability, mental health problems or mental, emotional or behavioural problems) and on the health of the family, access to health services (therapies, care and specialised medical treatment), relationships within the family (child-foster parent, relations with the siblings, relations with the relatives), the child's involvement in the daily activities of the family, ways of rewarding or sanctioning the child, relationship with the biological family. The last part of the questionnaire aimed at determining the attitude of children towards school, success or failure at school, behaviour in school and children's groups, how to spend leisure time and holidays, involvement of the children in community life, the child's comfort in the foster family, plans for the future.

The non-directive interview applied to pre-school children allowed the gathering of a large amount of data in a relatively short time providing a high degree of freedom of exploring the phenomenon in a complete manner and at the same time offering children freedom of expression during the interview.

The study involved a total of 25 foster families and 32 children who were then in placement and the procedure by which the participants were selected was theoretical sampling. The Ethics Agreement for this study was given by the General Directorate of Social Assistance and Child Protection Arges and each of the respondents were informed about the confidentiality of the information provided. All foster parents gave their written consent, being also informed about the right to refuse and/or remove their data at any time or to refuse to answer certain questions or discuss certain issues raised. All respondents, however, wanted to answer questions and discuss issues related to their lives. The interviews and questionnaires were applied to children in the presence of foster parents, with indefinite duration, giving participants more flexibility in expressing opinions. Moreover, during the interview efforts were made to ensure that both parents and children interviewed feel at ease, which made it possible for them to answer most questions.

\section{LIMITATIONS}

The limitations of this research may be grouped into several categories: limitations relating to the interpretation of results, limitations related to the method of research (questionnaire), limitations that are related to the theoretical and methodological issues specific to any study dealing with the subjective wellbeing of individuals. 
Specialised literature reflects the lack of an overarching conceptual framework by which to evaluate the effectiveness of treatment in foster homes (Bates et al., 1997). Interactions between foster parents and the foster child are likely to be a significant determinant of placement outcomes, but most research has focused on the individual characteristics of children and prospective families without looking at the characteristics of a good child-family match (Richard E. Redding, J.D.,Carrie Fried, M.A., Preston A. Britner, 2000).

Another limitation of the study is that it did not analyse the causal links that exist between various factors (children's relationships with family, friend or teachers, family structure, changes in the lives of children, the security of their environment, their participation in the systems with which they interact, values to which they aspire, their rights) and the subjective well-being of children, but I just looked at the association between these factors and the subjective well-being in general and satisfaction in various areas of children's lives.

Moreover, during this questionnaire, the children made a number of comments on some items included in the questionnaire and suggested eliminating or reformulating some of them, replacing them or adding items at some questions. The children's responses and suggestions demonstrated the importance of encouraging child participation and expression in the polls of their views about important aspects of their lives. Future research will be based on a consultation process with children (using qualitative methods) regarding topics and issues of life that are relevant to their age and their level of understanding of well-being. Such data would better reflect the position of children from different contexts of life and with different characteristics and would link academic study objectives, programs, policies for children and adolescents with their needs, aspirations, values and skills.

Beyond the usefulness of the data obtained, they must be examined carefully in the studies that will follow this research because they may be influenced by several aspects. For example, some difficulties may arise in the analysis of the subjective well-being of children, especially at this age (12 -16 years), considered the age of entry into adolescence, when they oscillate between the need for protection and autonomy, they are in a process of development at all levels of their life: cognitive, behavioural, emotional, moral, physical, and this has an impact on how they relate both to themselves and to others (family, friends, school, community). Moreover, children at this age are influenced by a number of models (school, group of friends, media, information and communication technologies - computer, internet, mobile phone) which, together with the context of the life they lead and the culture they belong to, can influence their perception of the life they have.

\section{ANALYSIS AND DISCUSSION}

There were applied a total of 43 questionnaires, 25 of which were applied to foster parents aged between 30 and 60 years, 18 of them to children between 7 and 16 years and 14 interviews were conducted with children aged 4 to 6 years. For the purposes of this study, foster families and their children were selected from the Arges County, based on the agreement given by the General Directorate of Social Assistance and Child Protection Arges.

The application of questionnaires to foster parents and children allowed an analysis of this problem from two points of view and a comparison of the results. If research had been performed from one perspective only then it would have been likely that the information obtained be subjective and less detailed on certain aspects. During the study special attention was paid to interviews and questionnaires applied to children so that the information obtained should be sufficient to produce an analysis of the quality of their lives.

The first questions aimed at identifying the material conditions a foster family had and at highlighting the things the child has access to. The most common things children mentioned in the questionnaire and interview were: access to the Internet, owning a mobile phone and holding one's own room.

Other items from the questions describe ways of rewarding or punishing children in professional foster care. About $50 \%$ of children claimed that they are praised verbally, without getting any material advantages in return, whilst others are given either money $(20 \%)$ or different gifts $(20 \%)$ or receive consent to go on trips or camps organized by various institutions: schools, NGOs, associations.

The fact that only $15 \%$ of them stat that occasionally they are punished by their parents for their behaviour show that the education methods applied by foster parents rely more on rewards and less on punishment. By examining the relationships and the parenting style adopted by foster parents and it was proved that the progress and well-being of children is positively associated with a democratic parenting style and negatively associated with an authoritarian and permissive style. It was also found that most children develop a secure attachment when the adoptive parents are more sensitive, empathetic, understanding and communicative.

Regarding ways of spending leisure time, $80 \%$ of them prefer to watch various TV programs and only $10 \%$ 
perform various activities within their group of friends. Among other ways of spending leisure time, mentioned by the children, we may add: tablet games, playing sports or engaging in various activities of their parents.

"Table 1". Items regarding the life quality of a child from foster family

\begin{tabular}{|lc|}
\hline & Percent \\
\hline The children have all they need in the new family & 100 \\
He/She is rewarded by his/her parents & 90 \\
The children are sometime punished by foster parents & 15 \\
The frequent method of educating a child in a foster family is democratic parenting & 100 \\
They spend their's free time watching TV & 80 \\
They spend their's free time with their friends & 10 \\
\hline
\end{tabular}

Not surprisingly, emotional and behavioural problems in foster children are negatively related to placement success. Foster children who exhibit normal attachment behaviours, good school conduct, who are better socialized and non-aggressive, and have experienced acute (rather than chronic) family problems precipitating their removal from the home, are more likely to have foster care placements that lasted at least 60 days and did not disrupt unexpectedly thereafter (Stone \& Stone, 1983).

In analysing the emotional state of children as an important and significant part of the study regarding the quality of their lives a number of variables were taken into account, these being related to the emotional problems and behavioural issues of a foster child in the context of the placement (age, age at entry into placement, history of neglect, abuse, abandonment) (Barber et al 2001; Webster et al .. 2000), to the characteristics of the foster parent (e.g., preparation and/or support received, the tremendous responsibility the latter has to uphold as a maternal assistant), as well as to the relationship between the foster family and the child.

In this context, Fernandez (2009) showed that the child's age upon entering foster care is associated with the degree of integration achieved within the family, with children who were younger at the start of the placement becoming better integrated. Accordingly, Tarren- Sweeney (2008) showed that one of the main predictors of behaviour problems was the child's age when entering foster care.

This study highlights the fact that the vast majority of children who are in foster care have already been exposed to conditions that undermined their chances for healthy development. Most of them grew up in poverty and were mistreated, this resulting in delayed development. As a result, about $75 \%$ of respondents feel very well in the new family, being aware of the fact that foster care can improve their problems. One consequence of this is that many of them have managed to establish relationships of attachment and friendship with the foster parents' children (about 93\%), feeling safe, happy and protected within the family (Table 2).

"Table 2" Investigation results -child's emotional state

\begin{tabular}{|c|c|c|}
\hline Questions & Answer & Rezults (\%) \\
\hline $\begin{array}{l}\text { Haw do you feel in a foster } \\
\text { family? }\end{array}$ & $\begin{array}{l}\text { Very good. } \\
\text { Good } \\
\text { Bad, I want to leave this } \\
\text { family }\end{array}$ & $\begin{array}{l}75 \\
25 \\
0\end{array}$ \\
\hline $\begin{array}{l}\text { Do you have a close } \\
\text { relationship with biological } \\
\text { children of foster family? }\end{array}$ & $\begin{array}{l}\text { Yes, I feel as a member } \\
\text { of this family. } \\
\text { No, we are not friends. }\end{array}$ & $\begin{array}{l}93 \\
7\end{array}$ \\
\hline $\begin{array}{l}\text { Parents foster are closet to you } \\
\text { can you talk with them about } \\
\text { your problems? }\end{array}$ & $\begin{array}{l}\text { Yes, they are a real } \\
\text { family for me. } \\
\text { No }\end{array}$ & $\begin{array}{l}90 \\
10\end{array}$ \\
\hline $\begin{array}{l}\text { Do you keep connection with } \\
\text { biological parents? }\end{array}$ & $\begin{array}{l}\text { Yes } \\
\text { No, never }\end{array}$ & $\begin{array}{l}81 \\
9\end{array}$ \\
\hline
\end{tabular}




\begin{tabular}{|l|l|l|}
\hline Haw do you feel in this family? & $\begin{array}{l}\text { I am very happy } \\
\text { I fell seif, protected } \\
\text { In this family my dreams } \\
\text { can come true } \\
\text { It is much better then in } \\
\text { my biological family. } \\
\text { I am unhappy }\end{array}$ & $\begin{array}{l}15 \\
21\end{array}$ \\
\hline What matters most in your life? & $\begin{array}{l}\text { Health } \\
\text { Money } \\
\text { Your family } \\
\text { Your friends } \\
\text { Education }\end{array}$ & $\begin{array}{l}40 \\
28\end{array}$ \\
& 0 \\
\hline
\end{tabular}

The foster children's relationship with the adoptive parents and the other children in the house has a significant impact upon their level of satisfaction with this form of protection. Children who feel close to their adoptive families were more satisfied with their foster care experience. Here, family warmth plays an important role and, when it stops, in circumstances such as the indifference of the foster family's biological children or favouritism towards them, there are negative effects on institutionalised children (Fanshel et al, 1990).

The ways through which their attempts of liaising with the biological family are carried out are various. Thus, this study has revealed that about $70 \%$ of children maintain relationships with their biological parents and this is achieved through visits they make with their foster parents to the biological, or a meeting is arranged with them at one of the centres under the authority of the General Directorate of Social Assistance and Child Protection of Arges. One of the important aspects in this objective is the biological family involvement in decisions made about the child, such as the child's transfer to another school, his/her enrolling into another educational cycle or his/her inclusion in a program of recovery.

As a result, the family environment in which they live provides a sense of protection and security that allows them to develop a positive self-esteem and improve their quality of life. Moreover, maintaining the link between foster children and their biological parents (where possible) is one of the most important and most difficult responsibilities of the foster parents and also crucial as it has a positive impact on most children and should be encouraged both for children under long-term placement and for temporary foster care (Davis, Landsverk, Newton \& Ganger, 1996; Hess, 1988).

\section{CONCLUSIONS}

The issue of investigation into the quality of children's lives in foster families is new and complicated, but the results augur well. The questionnaire is relatively simple and comprehensive, which makes it easier to evaluate the life quality of children placed in foster families. The fact that the matter is investigated from two perspectives and the existence of two different types of questionnaires give the opportunity to collect varied information and compare at least some of it. Divided in several separate parts, the questionnaire offers a description of the quality of life in these areas. The fact that a relationship of confidence was built between the investigator and the respondents contributed to the gathering of important and relevant information. But for a more detailed research one needs to apply other methods of investigation involving specialists in the area of psychology. The results obtained provide a lot of diverse information that in the future may help to develop and improve both the method itself and the research tools used in the method.

The placement of children in foster families has had a positive impact on children, though they changed their living environment and the school, they managed to make new friends, to establish relationships of attachment to the foster parents and their children. In many cases children "benefit" of extra-care and attention without the parents' having extra-resources, extra-training or extra-support. These special efforts and special environments are to create healthy environments for the development of babies and children, especially of children with disabilities. As a consequence, the children who managed to better integrate in this form of protection, having a high quality of life, are those who:

a) have less physical, emotional and behavioural problems 
b) have previously undergone less forms of protection

c) have managed to build good relationships with the foster family

d) have ties with the biological family.

Several characteristics were also identified in connection to the foster parents, namely their contributing to the well-being of children: parents who are motivated to become foster parents have effective parenting styles, good living conditions and benefit from support systems; they are emotionally stable and perceptive to the needs of the child.

These findings reinforce the idea that ensuring stability and effectiveness of this safeguard is closely related to the selection of adoptive parents, to the "match" between the family and the foster children and also to the empowering of foster children. Equally important is the role of society through the values that it promotes, as it can contribute to the integration of this category in the community and give them the right to life. It is therefore necessary to create a direct relationship between the family and society because family functionality in itself cannot be separated from the societal context. The family needs the support of other members of society. Often social perception of institutionalized children is not favourable and social inclusion still encounters various barriers, cultural and social.

Finally, child development and protection policies must be based on the existing strengths of children in foster care and of their families. These strengths must be identified when the child enters the system and the process of intervention is begun. Recognizing the strengths of children and the reliance upon them in direct interventions, administrative decisions and public policies is crucial for a healthy development and for the well-being of children.

\section{REFERENCE LIST}

Barber, J. G., Delfabbro, P. H., \& Cooper, L. L. (2001). The predictors of unsuccessful transition to foster care. Journal of Child Psychology and Psychiatry, 42(6), 785-790. doi:10.1111/1469-7610.00775.

Bates, B. C., English, D. J., \& Kouidou-Giles, S. (1997). Residential treatment and its alternatives: A review of the literature. Child and Youth Care Forum, 26, 7-51.

Buboltz, M., \& Whiren, A. P. (1984). The family of the handicapped: An ecological model for policy and practice. Family Relations, 33, 5-12.

Buzduce. D., (2010). Asistenta sociala a grupurilor de risc. Iasi: Editura Polirom

Davis, I.P., J. Landsverk, R. Newton, \& W. Ganger. (1996). Parental visiting and foster care reunification. Children and Youth Services Review, 18, 363-382.

Fanshel, D., Finch, S. J., \& Grundy, J. F. (1990). Foster children in a life course perspective. New York: Columbia University Press.

Fernandez, E. (2009). Children's wellbeing in care: Evidence from a longitudinal study of outcomes. Children and Youth Services Review, 31(10), 1092-1100. doi:10.1016/j.childyouth.2009.07. 010.

Gabor, P., \& Kammerer, K. (1983). Ameeting point: Developing treatment oriented foster care. Journal of Child Care, 1, 87-97.

Ghera, M. M., Marshall, P. J., Fox, N. A., Zeanah, C. H., Nelson, C. A., Smyke, A. T., \& Guthrie, D. (2009). The effects of foster care intervention on socially deprived institutionalized children's attention and positive affect: Results from the BEIP study. Journal of Child Psychology and Psychiatry, 50 (3), 246253.

Hess, P. (1988). Case and context: Determinants of planned visit frequency in foster family care. Child Welfare, 67, 311-326.

Ligarski, J. Mariusz, (2010). Investigations on the life quality of a child from a foster family: the research method, Qual Quan, Springer Science Pubulication, 44, 777-782 DOI 10.1007/s11135-009-9226-y.

Marshall, P. J., Reeb, B. C., Fox, N. A., Nelson, C. A., \& Zeanah, C. H. (2012). Effects of early intervention on EEG power and coherence in previously institutionalized children in Romania. Development and Psychopathology, 20 (3).

Nelson, C. A., Zeanah, C. H., Fox, N. A., Marshall, P. J., Smyke, A. T., \& Guthrie, D. (2007). Cognitive recovery in socially deprived young children: The Bucharest Early Intervention Project. Science, 318 (5858), 1937-1940. 
Petre, N. (2002), Familie de încredințare/plasamnet (familia foster), în Pop, L.M., (coord.), Dicționar de politici sociale, București: Editura Expert, p.332.

Richard E. Redding, J.D.,Carrie Fried, M.A., Preston A. Britner, (2000). Predictors of Placement Outcomes in Treatment Foster Care: Implications for Foster Parent Selection and Service Delivery Journal of Child and Family Studies, 9( 4), 425-447.

Smyke, A. T., Zeanah, C. H., Fox, N. A., Nelson, C. A., \& Guthrie, D. (2010). Placement in foster care enhances quality of attachment among young institutionalized children. Child Development, 81 (1), 212-223.

Tarren-Sweeney, M. (2008). Retrospective and concurrent predictors of the mental health of children in care. Children and Youth Services Review, 30(1), 1-25. doi:10.1016/j.childyouth.2007.05. 014.

Webster, D., Barth, R., \& Needell, B. (2000). Placement stability for children in out of home care: A longitudinal analysis. Child Welfare, 79(5), 615-/632. Retrieved from http://www.cwla.org/ articles/cwjabstracts.htm.

Zeanah, C. H., Egger, H. L., Smyke, A. T., Nelson, C. A., Fox, C. A., Marshall, P. J., \& Guthrie, D. (2009). Institutional rearing and psychiatric disorders in Romanian preschool children. Journal of American Psychiatry, $166,77$. 